\title{
Monitoring growth of Cellulomonas uda in solid state fermentations with Brewers' spent grain and optimization of the bioprocess
}

\author{
Alexander Akermann ${ }^{1}$, Jens Weiermueller ${ }^{1}$, Jonas Chodorski ${ }^{1}$, Malte Nestriepke ${ }^{1}$, Maria \\ Baclig$^{1}$, and Roland Ulber ${ }^{1}$
}

${ }^{1}$ TU Kaiserslautern

February 16, 2021

\begin{abstract}
Brewers' spent grain (BSG) is a low-value by-product of the brewing process, which is produced in large quantities every year. In this study, the lignocellulosic feedstock was used to run solid state fermentations with Cellulomonas uda. For aerobic processes, maximum cellulase activities of $0.98 \mathrm{nkat}[?] \mathrm{ml}^{-1}$, maximum xylanase activities of $5.00 \mathrm{nkat}[?] \mathrm{ml}^{-1}$ and cell yields of $0.22 \mathrm{~g}_{\mathrm{Cells}}[?] \mathrm{g}_{\mathrm{BSG}}{ }^{-1}$ were achieved. Under anaerobic conditions, enzyme activities and cell yields were lower, but valuable liquid products (organic acids, ethanol) were produced with a yield of $0.41 \mathrm{~g}_{\mathrm{Prod}}\left[\right.$ ?] $\mathrm{g}_{\mathrm{BSG}}{ }^{-1}$. The growth phase of the organisms was monitored by measuring extracellular concentrations of two fluorophores pyridoxin (aerobic) and tryptophan (anaerobic) and by cell count. By applying reductive conditions to the anaerobic approach, the ratio of ethanol to acetate was increased from 1.08 to $1.59 \mathrm{~mol}_{\mathrm{EtOH}}[?] \mathrm{mol}_{\mathrm{Ac}}{ }^{-1}$. This ratio was further improved to $9.2 \mathrm{~mol}_{\mathrm{EtOH}}[?] \mathrm{mol}_{\mathrm{Ac}}{ }^{-1}$ by lowering the $\mathrm{pH}$ from 7.4 to 5.0 without decreasing the final ethanol concentration. A scale up fermentation with 15w\% BSG instead of 5w\% BSG quadrupled the acetate concentration, whilst ethanol was removed by gas stripping. This study provides various ideas for optimizing and monitoring solid state fermentations, which can support feasibility and incorporation into holistic biorefining approaches in the future.
\end{abstract}

\section{Hosted file}

Main document_final.pdf available at https://authorea.com/users/396111/articles/509260monitoring-growth-of-cellulomonas-uda-in-solid-state-fermentations-with-brewers-spentgrain-and-optimization-of-the-bioprocess 


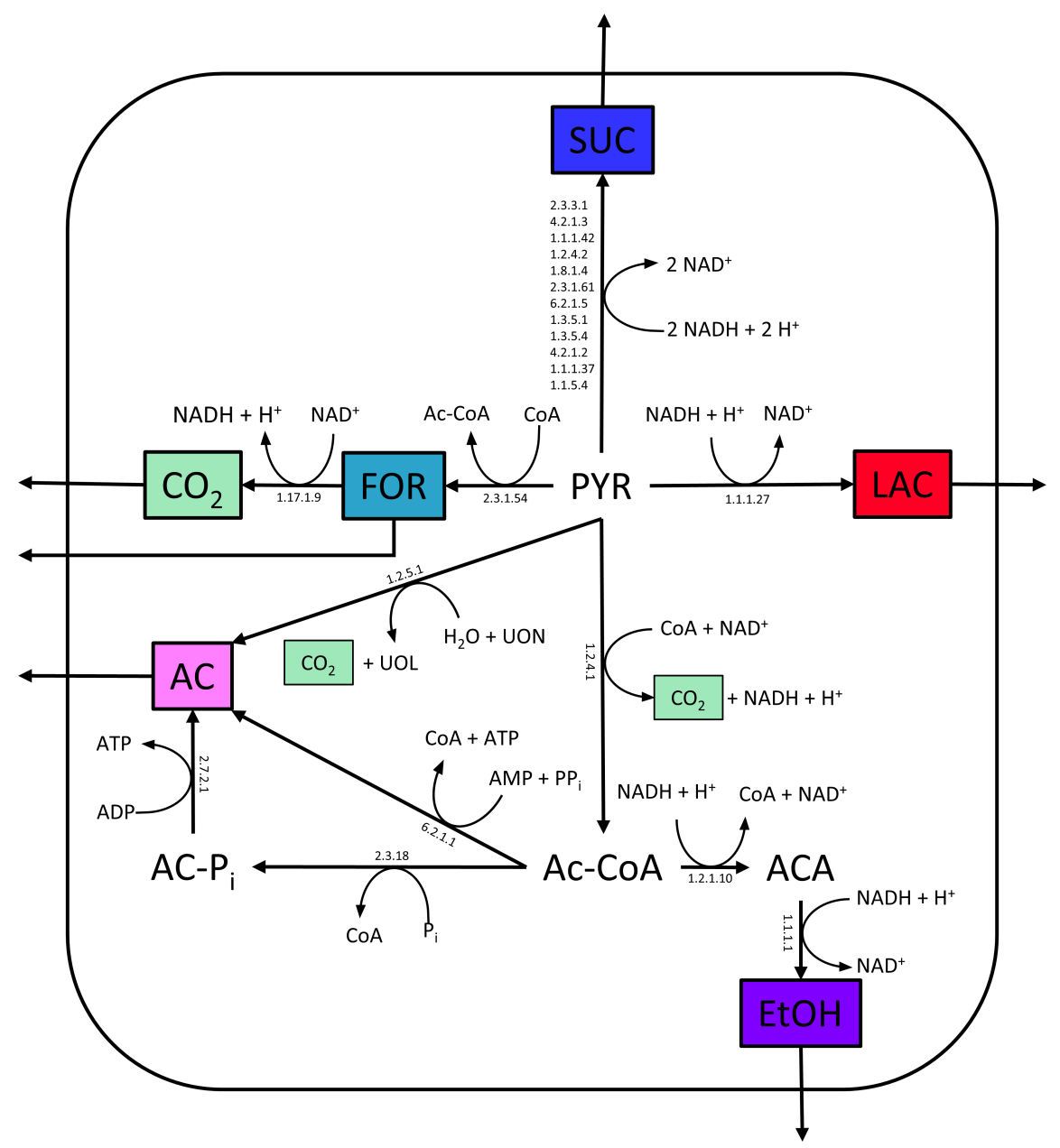



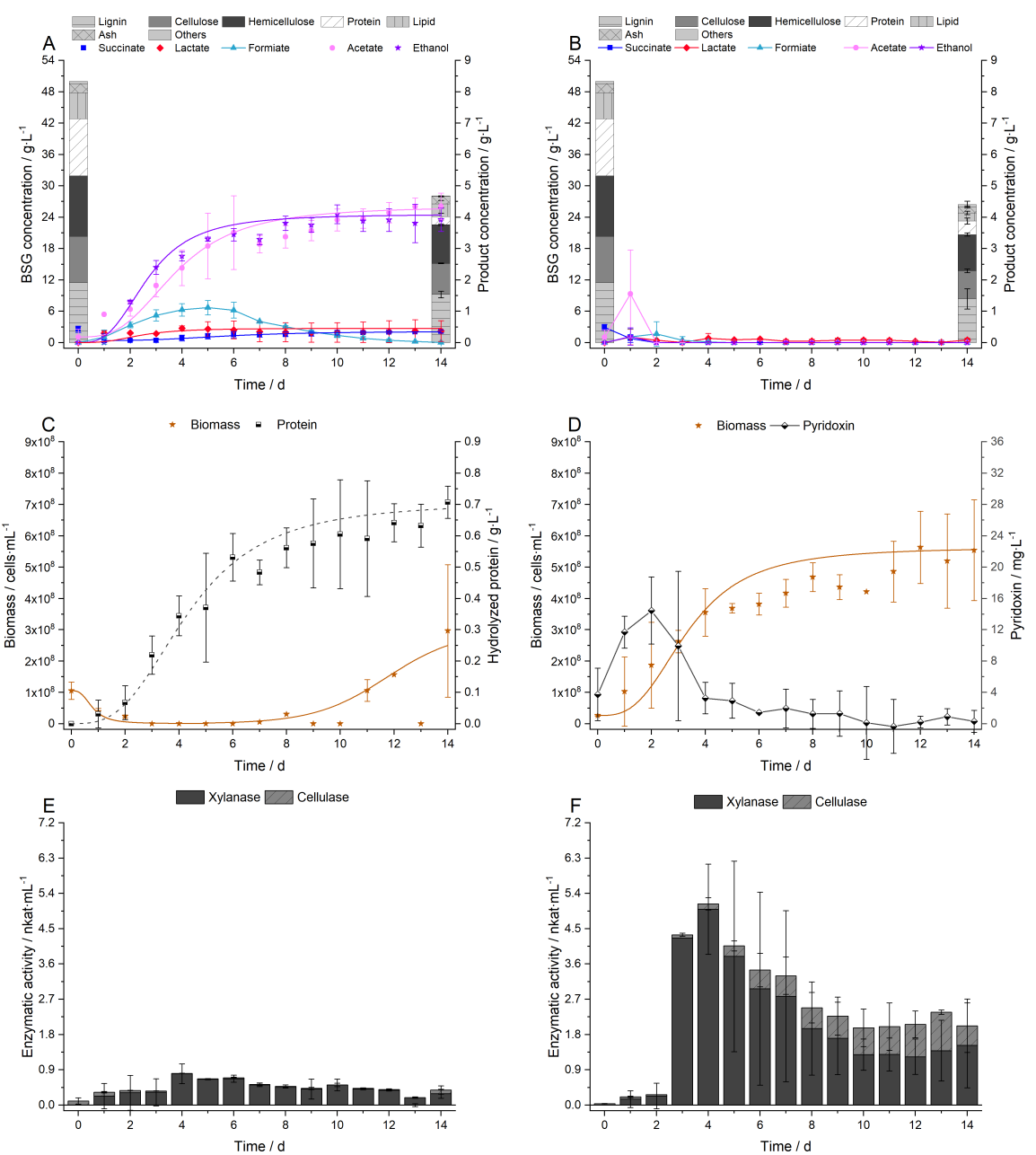

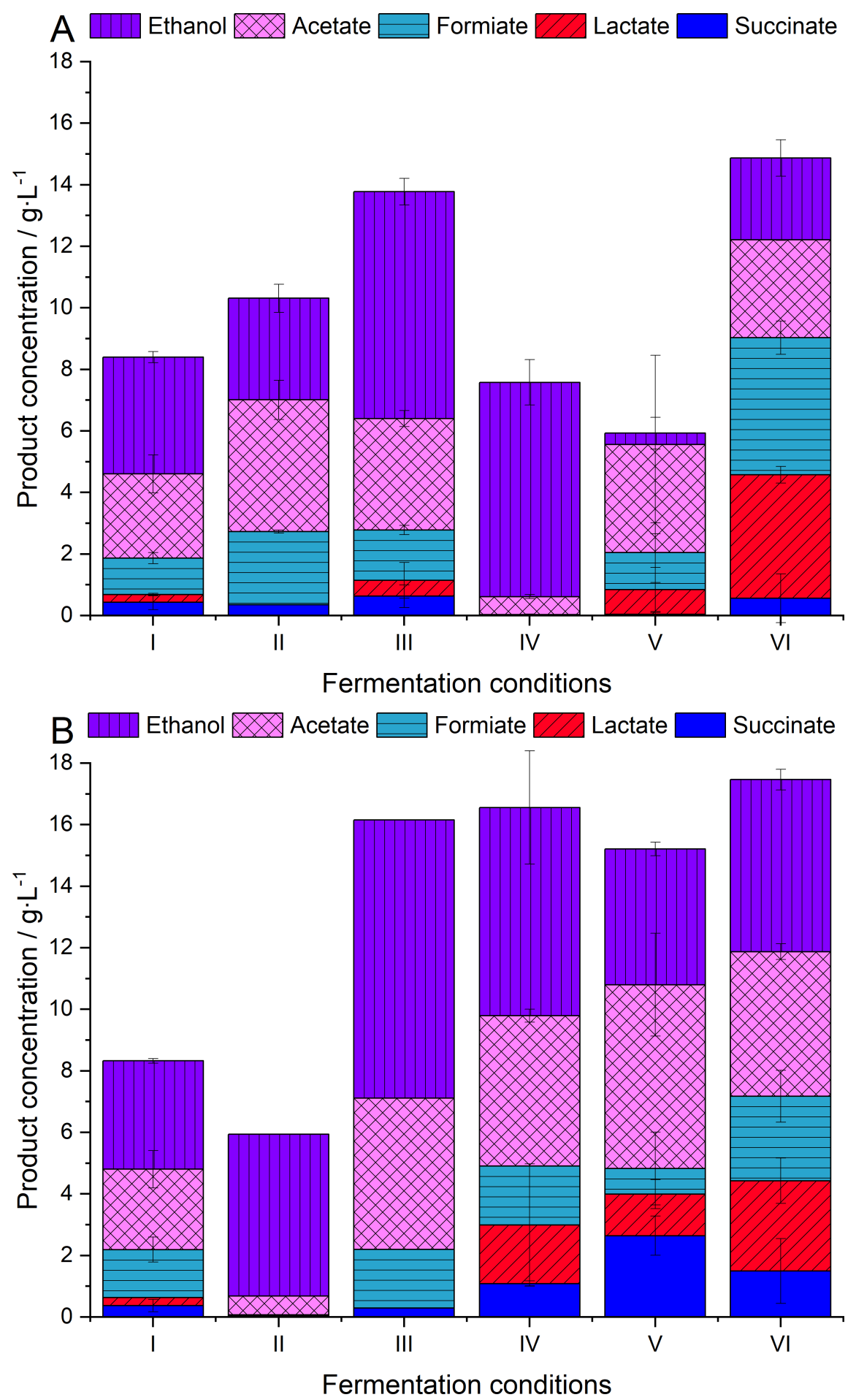

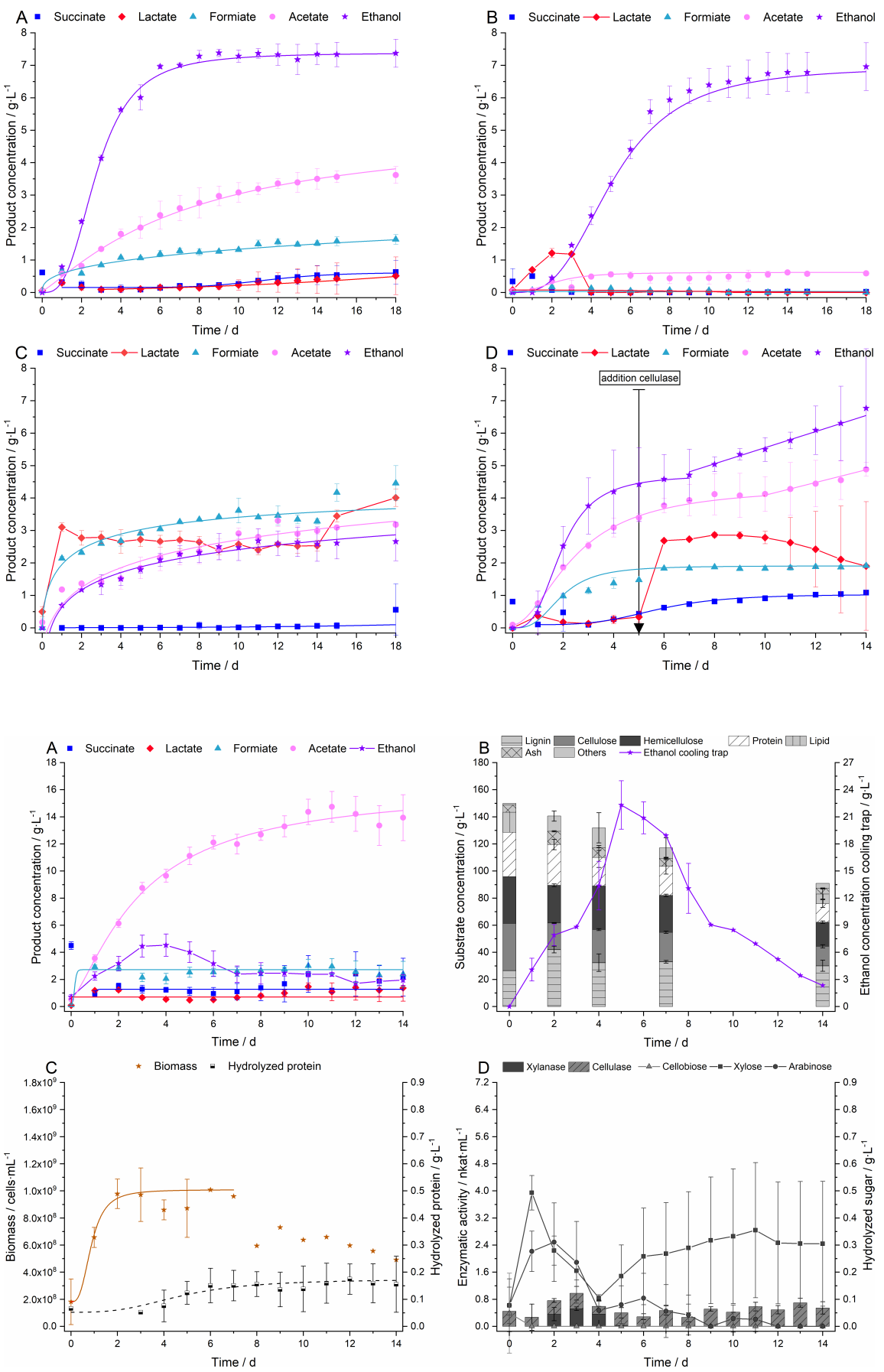